\title{
PADRONIZAÇÃO DA METODOLOGIA DE RUPTURA BASAL EM CUNHA PARA TOMBAMENTO DE PAINÉIS VERTICAIS NA LAVRA DE ROCHA ORNAMENTAL
}

\author{
Rafael Franco e Silva ' \\ Suelem Silva Rocha' \\ Alfredo César Vale de Araújo ' \\ Marcio Luiz Siqueira Campos Barros ' \\ Murilo Simonato de Assis ${ }^{2}$
}

\section{Resumo}

Desde a idade da pedra, a humanidade utiliza as rochas como ferramenta de trabalho, armamento para caça, pesca e em objetos sacros. Com o passar dos séculos as rochas foram ganhando novas aplicações, entre elas a de elemento ornamental, sendo usadas como esculturas e na construção de templos, até chegar aos dias atuais, em que as mesmas encontram-se bem difundidas. Esse emprego da rocha com fins ornamentais levou ao desenvolvimento, ainda na Idade Média, de uma tradição técnico-profissional na extração e beneficiamento de rochas ornamentais. A explotação de rocha ornamental pode ser realizada através de vários métodos e a escolha do método adequado é função do tipo de jazida na qual se trabalha a céu aberto, seja em matacões ou afloramentos rochosos. Tratando-se da lavra de um afloramento rochoso através de bancadas ultra-altas, com altura superior a $20 \mathrm{~m}$, tem-se uma peculiaridade que é o método de derrubada do painel vertical com o auxílio da técnica denominada "boca de lobo", que é muito difundida na prática, entretanto realizada sem parâmetro algum de padronização. Neste contexto, com o objetivo de uniformizar a metodologia de tombamento dos paineis através da técnica "boca de lobo" realizou-se um estudo e, diante da análise da prática em campo, foi possível relacionar os dados obtidos formulando uma nova equação permitindo a qualquer profissional aperfeiçoar o processo de explotação de blocos nas pedreiras de Rocha Ornamental.

Palavras-chave: Rocha ornamental; Lavra de paineis verticais; "Boca de Lobo".

\section{STANDARDIZATION OF WEDGE BASAL RUPTURE METHODOLOGY FOR VERTICAL PANEL TIPPING IN NATURAL STONE QUARRYING}

\begin{abstract}
Since the stone age, humanity has used rocks as a working tool, weapons for hunting, fishing and sacred objects. Over the centuries the rocks have been gaining new applications, among them the ornamental element, being used as sculptures and building temples, until the present day, in which they are well diffused. This use of rock with ornamental purposes led to the development, even in the Middle Ages period, of a technical-professional tradition in the natural stones extraction and processing. The exploitation of natural stone can be performed through several methods and the choice of the appropriate method is a function of the type of open pit, whether on boulders or rock outcrops. In the case of a rock outcrop mining through ultra-high benches, with height greater than $20 \mathrm{~m}$, there is a peculiarity that is the method of vertical panel tipping with the aid of the technique called "wolf's mouth", which is very widespread in practice, however performed without any standardization parameters. In this context, a study was carried out in order to try to standardize the method of tipping the panels through the "wolf's mouth", and, in face of the analysis of the field practice, it was possible to relate the data obtained by formulating a new equation, allowing any professional to improve the process of exploiting blocks in Natural Stones quarries.
\end{abstract}

Keywords: Ornamental rock; Vertical panels mining; "Wolf mouth".

'Programa de Pós-graduação em Engenharia Mineral - PPGEMinas, Universidade Federal de Pernambuco - UFPE, Recife, PE, Brasil.

E-mail: rafaelfrancosil@gmail.com

${ }^{2}$ Faculdade Multivix, Nova Venécia, ES, Brasil.

2176-1523 (c) 2019 Associação Brasileira de Metalurgia, Materiais e Mineração. Publicado pela ABM. Este é um artigo de acesso aberto distribuído sob os termos da licença Creative Commons CC BY-NC-ND (Attribution-NonCommercial-NoDerivs) - https:// creativecommons.org/licenses/by-nc-nd/4.0\%. 


\section{INTRODUÇÃO}

Desde os primórdios o homem utiliza as rochas para construção de suas ferramentas de trabalho e suas armas. Com o passar dos séculos e o avanço das civilizações como a egípcia, a grega e a romana, essa realidade foi mudando e o homem começou a utilizar as rochas em esculturas e estruturas de edificações, as quais muitas vezes consistiam em templos para adorar seus deuses. Assim, com a mudança da aplicabilidade das rochas nas mais diversas atividades pela homem, houve uma alteração da forma de extração desses materiais, que passaram a ter valorizado não somente sua beleza, mas também suas qualidades estruturais [I].

Entretanto o uso das rochas como elemento ornamental na antiguidade foi bastante restrito devido ao sistema de propriedade das minas e das técnicas disponíveis para sua extração. A evolução e difusão das metodologias e técnicas desenvolvidas na Grécia e no Egito iniciou-se com a expansão do Império Romano e possibilitaram a extração de calcários e mármores de Portugal, e a partir de então se desenvolveu uma tradição técnico-profissional na extração e beneficiamento de rochas ornamentais, especificamente de mármores devido às tecnologias disponíveis. Foi somente a partir do século $X X$ que a evolução tecnológica possibilitou o aproveitamento de materiais mais duros, como as rochas conhecidas comercialmente por granitos, bem como o desdobramento destes materiais em chapas que podem ser cortadas e utilizadas em pisos e fachadas [2].

O processo de extração de blocos de rochas ornamentais requer a avaliação de uma série de fatores, principalmente com relação à forma e dimensões em que este material se encontra na natureza, que pode ser na forma de matacões ou afloramento rochoso. Para a lavra de um afloramento rochoso existem diversas técnicas que podem ser utilizadas, mas será abordada no trabalho a explotação em meia encosta, que pode ser desenvolvida em bancadas baixas, altas e ultra-altas (paineis verticais).

A lavra por bancadas ultra-altas é utilizada em relevos mais íngremes, e os painéis verticais com as tecnologias atuais já atingiram $94 \mathrm{~m}$ de altura. Nesta metodologia trabalha-se com uma única bancada e a extração do painel vertical requer, para o seu tombamento, a utilização de um método conhecido como "boca de lobo" que consiste na desestabilização da base do painel através da abertura de uma cunha, que é detonada, descalçando e desestabilizando o painel, jogando-o no chão em cima de uma "cama" para amortecer a sua queda [3].

Esta "cama" é confeccionada com material terroso estéril e pedaços de blocos de granitos, não tendo em sua composição material orgânico, e sua função é a de evitar a quebra do painel e a geração de micro fissuras induzidas pelo choque bem como ajudar posteriormente a operação de esquadrejamento, permitindo o corte com fio diamantado. Sua largura e comprimento devem ter dimensões em concordância com as dimensões do painel, assim como seu formato que tem o lado mais próximo à base do painel vertical mais baixo e o lado oposto mais alto. Este formato e altura são determinados de forma empírica pelos responsáveis em derrubar o painel vertical, não existindo um estudo mais aprofundado para seu dimensionamento.

Entretanto, a técnica "boca de lobo" como metodologia de tombamento dos painéis verticais vem sendo praticada sem parâmetro algum de padronização pelas diversas empresas da indústria de rochas ornamentais, o que pode acarretar em perda de material em uma "boca de lobo" muito grande ou ainda pode acontecer de o painel não se desprender $\mathrm{e}$ assim não ocorrer o seu tombamento.

Diante deste contexto, realizou-se um estudo com - objetivo de padronizar a utilização da "boca de lobo" melhorando o processo de explotação de rocha ornamental em uma pedreira no noroeste do estado do Espírito Santo [3].

\section{METODOLOGIA}

Para realizar a padronização da técnica "boca de lobo" foram coletadas informações como altura, largura e comprimento dos painéis verticais da lavra, assim como a altura das bocas de lobo nas frentes de extração em pedreiras de rocha ornamental no noroeste do estado do Espírito Santo que utiliza este método de lavra, no ano de 2017.

\section{I Lavra por Painéis Verticais}

O método de bancadas ultra-altas é um método relativamente novo, que vem sendo aplicado em pedreiras de granito no norte/noroeste do estado do Espírito Santo (Figura I). A aplicação deste método de lavra vem ganhando cada vez mais espaço dentre os métodos de lavra conhecidos, por ter como características sua alta produtividade e boa aplicabilidade em relevos acidentados e principalmente em encostas íngremes [4].

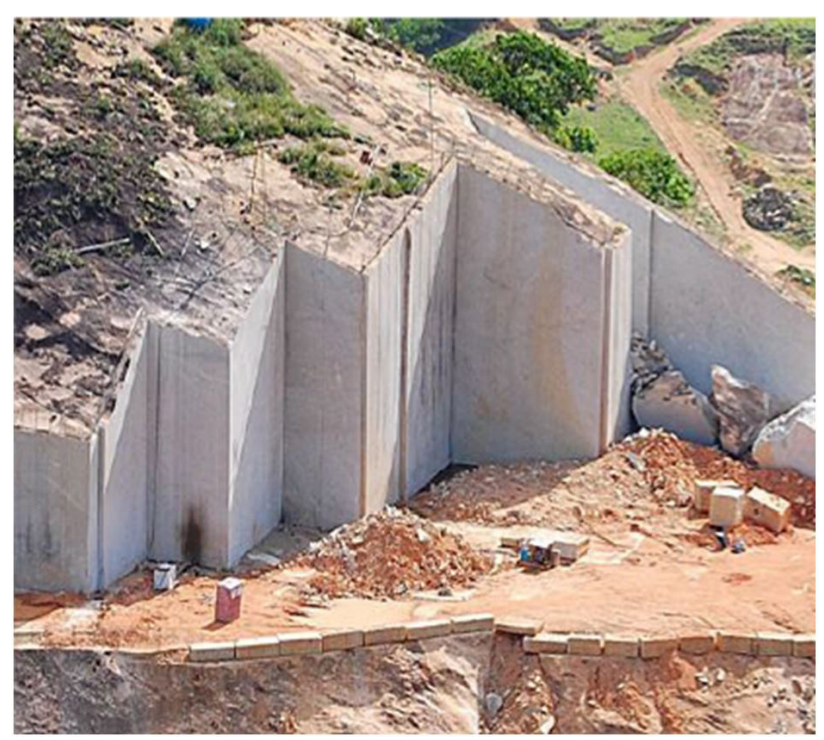

Figura I. Paineis verticais em uma pedreira no Espírito Santo [4]. 
$\mathrm{Na}$ pedreira em questão a extração dos painéis ocorre em etapas. Na primeira etapa é realizado um furo vetical com sonda rotativa via úmida devido à sua grande altura, minimizando desta forma os desvios de perfuração. $\mathrm{Na}$ segunda etapa deve-se realizar furos horizontais com martelo pneumático concorrentes com os furos realizados anteriormente, como pode ser obsevado na figura 2 , o que torna o trabalho muito complexo.

Após esses furos se encontrarem, se passa uma guia, normalmente um fio de náilon auxiliado por ar comprimido, onde se introduz o fio diamantado, para que então se possa realizar o corte do painel. $O$ primeiro corte a ser realizado é o horizontal (levante), posteriormente o corte lateral e finalmente o corte da face trincante do painel vertical (Figura 3).

Para tombamento do painel, após o mesmo estar separado do maciço rochoso, realiza-se o corte da "boca de lobo", que pode ser através do fio diamantado ou com martelo pneumático, ambos, vão utilizar explosivos para realizar o desmonte da "boca de lobo" e desestabilizar o painel vertical. A "boca de lobo" é um método não convencional que deve ser utilizado devido à elevada altura do painel vertical, visando à desestabilização do mesmo fazendo

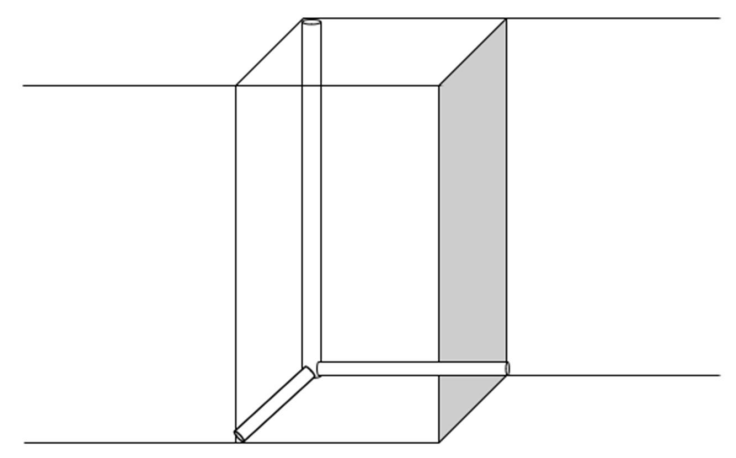

Figura 2. Furo I (na vertical) e furo 2 e 3 (na horizontal) [5].

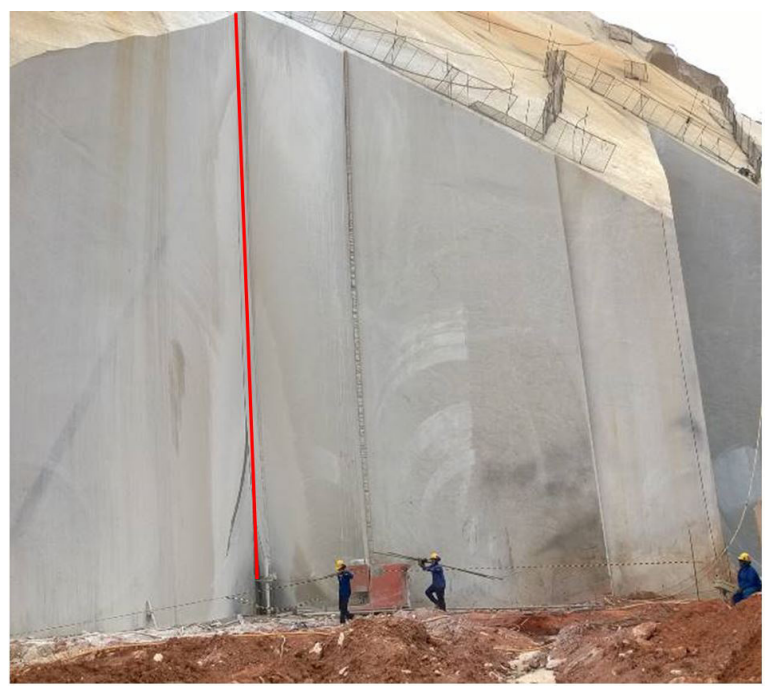

Figura 3. Em vermelho corte com fio diamantado na vertical, da região trincante do painel vertical. com que o centro de massa do painel ultrapasse a base do painel causando assim sua desestabilização e tombamento.

\subsection{Execução da “Boca de lobo” com Martelo Pneumático}

Utilizando martelos pneumáticos, confecciona-se um plano de fratura, com execução de vários furos paralelos com uma inclinação de $30^{\circ}$ em relação ao plano horizontal na base da prancha (Figura 4). Estes furos devem ser longos o suficiente para ultrapassar mais da metade da espessura do painel vertical.

Segundo Vidal et. al. [2], a "boca de lobo" deve ter uma altura de aproximadamente $0,5 \mathrm{~m}$, ângulo de $30^{\circ}$ e comprimento que deve ultrapassar metade da espessura da prancha (Figura 5). A utilização de explosivos para desestabilizar a "boca de lobo" ocorrerá através do próprio plano de fratura, criado na perfuração com os martelos.

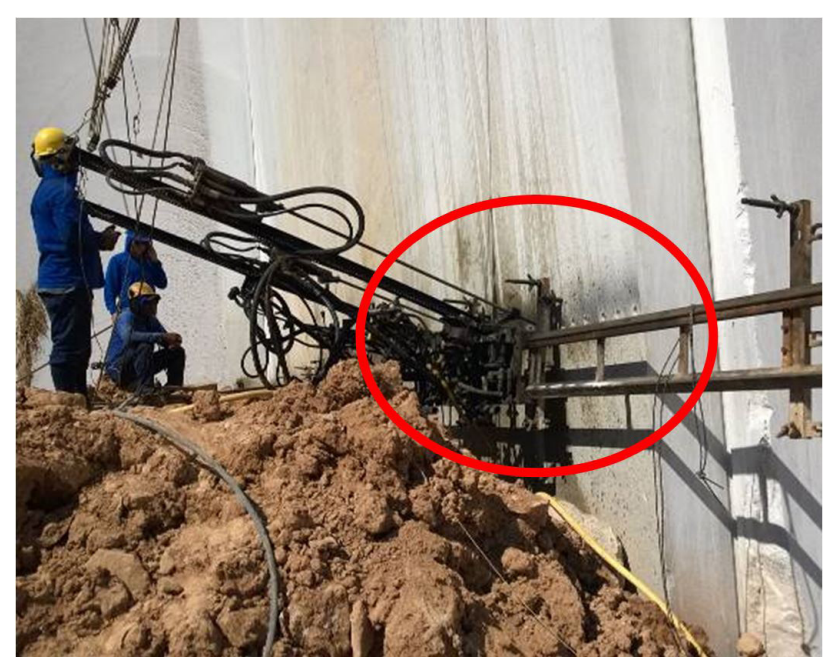

Figura 4. Perfuração inclinada com martelo pneumatico (destacado em vermelho), com ângulo aproximado de $30^{\circ}$ para formar a "boca de lobo".

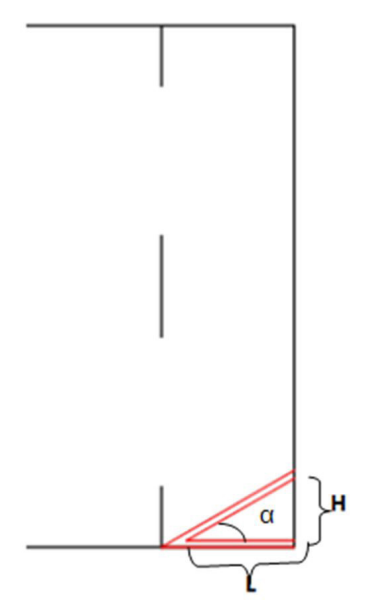

Figura 5. Corte da "boca de lobo" onde temos $\mathrm{H}=$ Altura da "boca de lobo", $\mathrm{L}=$ Largura da "boca de lobo" e $\alpha=$ Angulo da "boca de lobo", possibilitando encontrar a altura da "boca de lobo" através da equação $H=\operatorname{tg} \alpha \times L$. 


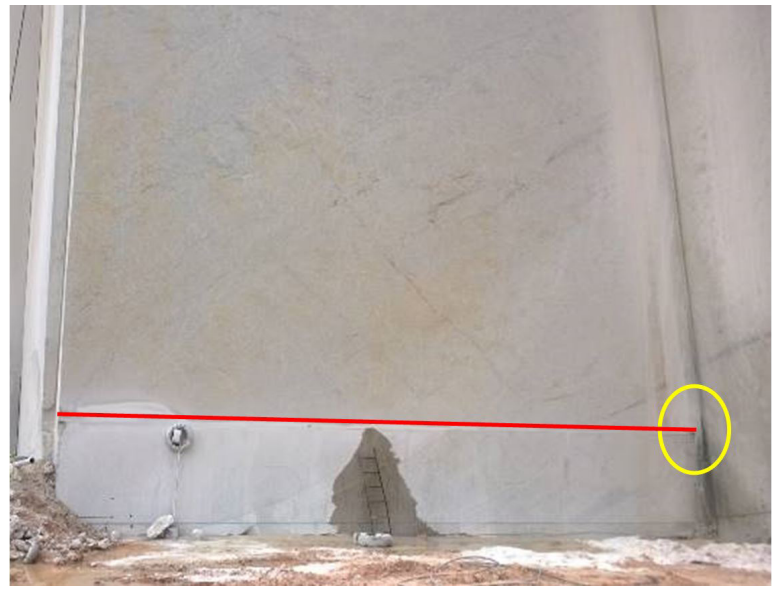

Figura 6. Imagem frontal da "boca de lobo" cortada com fio diamantado (em destaque, em vermelho), assim como pode ser visto em amarelo o furo inclinado.

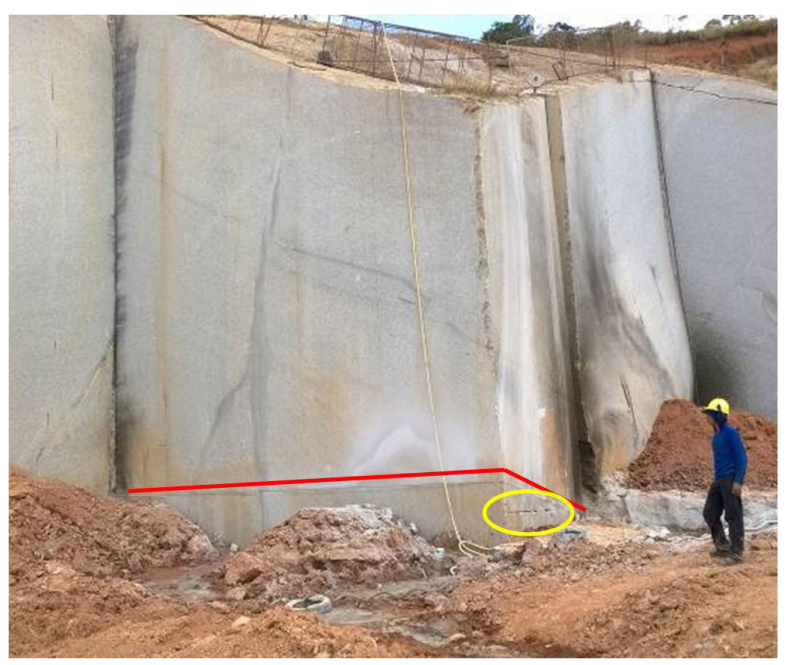

Figura 7. "Boca de lobo" cortada com fio diamantado em vermelho e perfuração lateral para inserção de explosivos em amarelo.

\subsection{Execução da "Boca de lobo" com Fio Diamantado}

Para confecção da "boca de lobo" com fio diamantado, o operador de martelo faz um único furo horizontal na parte lateral do painel vertical contemplando todo o comprimento do painel. Em seguida faz um único furo inclinado na frente do painel vertical na altura desejada da "boca de lobo", de modo que os dois furos se encontrem. Após executados estes dois furos, com o auxílio de um fio de nailon e ar comprimido passa-se o fio diamantado por eles e executa-se o corte da cunha ("boca de lobo"), separando a mesma do painel vertical (Figura 6).

Para que ocorra a desestabilização do painel vertical, após o corte com fio diamantado é necessário perfurar a lateral da "boca de lobo" para inserção de explosivo, se a "boca de lobo" tiver altura menor que I $\mathrm{m}$ se faz uma unica linha de furo, Caso a altura seja maior que Im faz-se duas ou tres linhas de furo no formato pé de galinha para inserção da pólvora (como pode ser visto na figura 7). Com o explosivo já inserido nos furos é feita toda a amarração com cordel, executa-se o desmonte da "boca de lobo", promovendo a desestabilização do centro de massa do painél vertical levando o mesmo a cair sobre uma cama de amortecimento.

Contudo, estas especificações não levam em consideração as dimensões do painel vertical que está sendo lavrado, o que não garante que a "boca de lobo" desestabilizará $\circ$ painel e, consequentemente, o mesmo poderá não tombar. Assim, foram coletadas as dimensões dos paineis e as alturas reais das "bocas de lobo" utilizadas na pedreira em estudo, criando uma relação empírica para a padronização da confecção das "bocas de lobo".

\section{RESULTADOS E DISCUSSÃO}

Com o levantamento dos dados em campo obteve-se a altura real da "boca de lobo". Assumindo os dados reais da tabela I, foi desenvolvida uma nova relação entre a largura da "boca de lobo" e a sua altura com o objetivo de

Tabela I. Dados obtidos na frente de extração

\begin{tabular}{|c|c|c|c|c|c|}
\hline Bancada & $A(m)$ & $L(m)$ & $\operatorname{Ar}(\mathrm{m})$ & $C(m)$ & $\mathrm{Ar} / \mathrm{L}$ \\
\hline 이 & 54,00 & 12,00 & 4,00 & 38,00 & 0,33 \\
\hline 02 & 50,00 & 10,00 & 3,00 & 15,00 & 0,30 \\
\hline 03 & 27,00 & 6,00 & 2,20 & 23,60 & 0,37 \\
\hline \multirow[t]{2}{*}{04} & 23,00 & 6,00 & 2,00 & 13,00 & 0,33 \\
\hline & & & & Média I & 0,33 \\
\hline 05 & 57,00 & 12,00 & 2,00 & 21,00 & 0,17 \\
\hline 06 & 78,00 & 15,00 & 2,50 & 22,00 & 0,17 \\
\hline 07 & 57,00 & 13,00 & 2,00 & 23,00 & 0,15 \\
\hline 08 & 64,00 & 14,00 & 2,40 & 29,00 & 0,17 \\
\hline 09 & 74,00 & 12,00 & 2,50 & 15,00 & 0,21 \\
\hline \multirow[t]{2}{*}{10} & 94,00 & 15,00 & 2,50 & 18,00 & 0,17 \\
\hline & & & & Média 2 & 0,17 \\
\hline
\end{tabular}

onde: $\mathrm{A}$ = altura do painel vertical, $\mathrm{L}=$ largura do painel vertical, $\mathrm{Ar}=$ altura real da "boca de lobo" (obtida na frente de extração), $\mathrm{C}=$ comprimento do painel vertical e $\mathrm{Ar} / \mathrm{L}=$ relação altura da "boca de lobo" pela largura da mesma, Média I = painéis variando de $20 \mathrm{~m}$ a $55 \mathrm{~m}$ e Média $2=$ painéis variando de $55 \mathrm{~m}$ a $94 \mathrm{~m}$. 
uniformizar a construção de "bocas de lobo" nas pedreiras de rocha ornamental, para que se garanta que no momento do desmonte a mesma descalce o painel vertical, levando-o ao tombamento.

Após a verificação de que o valor da altura real da "boca de lobo" é superior à altura dada pelo modelo existente, proposto por Vidal et al. [2], que é 0,5 m, considerou-se que o modelo anterior é válido apenas quando o painel vertical tiver em sua largura a dimensão de um dos lados do bloco final, mas com o aumento das dimensões deste painel, este modelo perde sua validade.

As novas equações I e 2 propostas, levam em consideração a relação entre a altura da "boca de lobo" e sua largura, resultando em:

Para alturas variando de $20 \mathrm{~m}$ a $55 \mathrm{~m}$ :

$A_{r}=0,33 \times L$

Para alturas variando de $55 \mathrm{~m}$ a $94 \mathrm{~m}$ :

$A_{r}=0,17 \times L$

\section{CONCLUSÕES}

A realização do trabalho possibilitou a verificação de que o modelo empírico existente para construção de "bocas de lobo" para tombamento de painéis verticais não é aplicável em todas as situações por não levar em consideração as dimensões do painel a ser tombado, enquanto que as observações em campo permitiram concluir que a largura do painel $(L)$ influencia diretamente no ângulo do plano da "boca de lobo" com a horizontal e, consequentemente, a altura da "boca de lobo".

O novo modelo empírico proposto leva em consideração a desestabilização do centro de gravidade do painel vertical, e foi construído a partir de dados reais obtidos nas frentes de extração das pedreiras de rochas ornamentais, o que permite obter a altura ideal para que o painel vertical seja desestabilizado e evitar que se construam "bocas de lobo" com alturas exageradas levando à perda de material de rocha ornamental e aumento no comprimento dos furos da "boca de lobo".

Também pode ser observado que independentemente da altura do painel vertical $(A)$, para alturas variando de $20,00 \mathrm{~m}$ até $55,00 \mathrm{~m}$ a altura da "boca de lobo" varia de $2,00 \mathrm{~m}$ a 4,00 $\mathrm{m}$ e a partir de 55,0 $\mathrm{m}$ a altura da "boca de lobo" deve variar entre $2,00 \mathrm{~m}$ a $2,50 \mathrm{~m}$, sendo mais que suficiente para promover a desestabilização do painel vertical.

\section{REFERÊNCIAS}

I Jimeno CL, Jimeno EL, Bermúdez PG. Manual de Perfuración y Voladura de Rocas. Madri: The Bookman; 20 I 3

2 Vidal FWH, Azevedo HCA, Castro NF. Tecnologia de rochas ornamentais: pesquisa, lavra e beneficiamento. Rio de Janeiro: CETEM/MCTI; 2014.

3 Maior RSM. Panorama da Mineração de Rochas Ornamentais no Estado do Espírito Santo com Ênfase na Lavra por Bancadas Ultra Alta. [Dissertação de Mestrado]. Recife: Universidade Federal de Pernambuco; 2013.

4 Novaes RC, Maior GRS. Viabilidade técnica e econômica da implementação do método de lavra de painéis verticais em comparação com o método de bancada regulares de rocha ornamental. In: Centro de Tecnologia Mineral. Anais do $9^{\circ}$ Simpósio de Rocha Ornamental do Nordeste; 2016 Abril 10-I3; João Pessoa, Brasil. Brasília: CETEM/MCTI; 2016. p. 83-91

5 Fazolo HP, Maior GRS. Aplicação da Metodologia de Lavra de Rocha Ornamental por Bancadas Ultra Altas nas Minerações de Granito no Norte do Espírito Santo. In: Centro de Tecnologia Mineral. Anais do $9 \circ$ Simpósio de Rocha Ornamental do Nordeste; 2016 Abril I0-I3; João Pessoa, Brasil. Brasília: CETEM/MCTI; 20I6. p. 347-355.

Recebido em: 29 Nov. 2017

Aceito em: 30 Abr. 2018 